\title{
Outcome of childhood malignancies at the University of Port Harcourt Teaching Hospital: a call for implementation of palliative care.
}

\author{
Gracia K. Eke ${ }^{1}$, Nwadiuto A. Akani ${ }^{2}$
}

1. Department of Paediatrics, University of Port Harcourt Teaching Hospital, Nigeria.

2. Institute of Maternal and Child Health, University of Port Harcourt, Nigeria.

\begin{abstract}
Background: Cancers in children are yet to be recognised as an important cause of childhood morbidity and mortality in developing countries where more than $70 \%$ of the world annual cases occur. Despite the limited resources and whatever the projected outcome, children with cancer need treatment, be it curative or palliative.

Objectives: To determine outcome of cancers in children at the UPTH; identify factors that influence outcome, highlight the need for palliative care.

Method: A retrospective study of cases of childhood malignancies admitted into Paediatric Oncology unit of UPTH over a two year period. Clinical profile of patients and outcome were analyzed using SPSS version 20.0.

Results: Sixty cases were analysed: 35(58.3\%) males, 25(41.7\%) females giving a M:F ratio of 1.4:1. Under-fives constituted $55 \%$. Twenty-seven (45\%) patients presented within 4 weeks of onset of symptoms. Median duration of symptoms before presentation was 8 weeks while $36(60 \%)$ had metastatic disease at diagnosis. Twenty patients $(33.3 \%)$ defaulted with or without specific treatment. Mortality was recorded in $26(43.4 \%)$ of cases.

Conclusion: There were more cases of cancer amongst under-fives with male preponderance. Late presentation, financial constraints and high default rate were contributory factors to poor outcome in most cases. Lack of palliative care left many families to face their sufferings.

Keywords: Outcome, childhood malignancies, implementation, palliative care.

DOI: http://dx.doi.org/10.4314/ahs.v16i1.10

Cite as: Eke GK, Akani NA. Outcome of childhood malignancies at the University of Port Harcourt Teaching Hospital:a call for implementation of palliative care. Afri Health Sci. 2016;16(1): 75-82. http:/ / dx.doi.org/10.4314/abs.v16i1.10
\end{abstract}

\section{Introduction}

More than 200,000 new cases of childhood cancers occur per year worldwide, with more than $70 \%$ of them happening in the developing world where mortality is approximately $80 \%$ in low resource settings, or even $90 \%$ in the world's poorest countries. ${ }^{1,2,3}$ In industrialized countries on the other hand, with a mortality of approximately $20 \%$, more than $70 \%$ of affected children become long-term survivors. ${ }^{1,2}$

In most developing countries, they are yet to be recognised either as an important cause of childhood mortal-
Corresponding author:
Gracia K. Eke,
Department of Paediatrics,
University of Port Harcourt
Teaching Hospital, Nigeria.
Phone: +234-8037097981
E-mail: kergracia@yahoo.com

ity or a significant public health issue due to many other competing causes of death: infectious diseases and malnutrition. ${ }^{1,4,5}$ Besides, the management of cancers still faces numerous challenges, ranging from poor healthcare infrastructure and diagnostic facilities, high cost of drugs and investigations, to scarcity of cancer care specialists. Other factors include ignorance, poverty, cultural beliefs and consultation of traditional healers which seem to be the major factors behind late presentation., The burden of cancer in Nigeria is unknown mainly because of lack of statistics or under-reporting.

Often times families faced with the diagnosis of cancer would prefer to go home rather than spend their time and little resources in the hospital with the presumption that the disease is incurable. This is, despite the fact that patients' suffering could still be relieved with remedies that are affordable and available, through palliative care which still remains the only hope and humanitarian relief to very many patients, including those with chronic or incurable diseases, especially in the terminal stages. ${ }^{7}$ 
Palliative care which offers services that are appropriate for people with life limiting conditions from the point of diagnosis, improves the quality of life of patients and their families. It is also appropriate for children as described by the World Health Organisation (WHO). ${ }^{8}$ Today, however, provision of palliative care on the African continent is inconsistent, often provided from isolated centres of excellence rather than integrated into the mainstream health-care system. ${ }^{9}$

In Nigeria, the concept of palliative care is relatively new, with services springing up in some tertiary health institutions in recent time. The coverage of the program is low, and palliative care services are mainly limited to patients who attend the tertiary hospitals, while they are non-existent at the secondary and primary health care levels. Some Non-Government Organisations (NGO) based and privately owned palliative care facilities also do exist.

Furthermore, the inadequate awareness of palliative care within the health profession, policy makers and general populace, contribute to the deprivation of the benefits of its services to majority of patients who need them.

This study was carried out in a tertiary hospital in the Niger Delta region of Nigeria to determine the outcome of cancers seen in children, to identify factors that influence outcome and to highlight the need for implementation of palliative care in the management of paediatric cancers.

\section{Patients and methods}

The study was conducted at the University of Port Harcourt Teaching Hospital (UPTH), a tertiary care hospital which serves as a general/referral centre for patients from within Rivers State, with its under-15 population of $2,437,138$ ( $47 \%$ of its population $)^{10}$ and neighbouring states. It is situated in the Niger Delta region of
Nigeria, an oil producing area with petroleum exploration and exploitation activities, including recurrent oil spillages in the communities with the attendant release of noxious metabolites in the environment.

In this retrospective study, all cases of childhood malignancies admitted into the Oncology unit of the Paediatric Department, UPTH, from January 2011 to December 2012 were reviewed. Approval was obtained from medical ethics committee of the hospital. Patients were identified from nurses records and data on each patient collected from hospital notes.

Variables studied included age at diagnosis, gender, socio-economic status, duration of illness, presence of metastases at presentation, treatment and outcome of treatment.

Patients were grouped into social classes according to the system of Oyedeji ${ }^{11}$ using educational levels and occupation of parents. Those in socioeconomic classes I and II were grouped as high; those in III as middle and those in IV and V as low income groups.

Metastases were identified clinically and/or radiologically. Children with Leukaemias were grouped with those having metastatic disease at diagnosis. ${ }^{12}$ Patients who were not seen in the 6 months preceeding the study were considered lost to follow-up.

Data was entered into a Microsoft Excel Spread Sheet and analyzed using SPSS version 20.0. Chi-Square test was used to test for significance. $\mathrm{P}$ values $<0.05$ were considered significant. Results were presented using tables and charts.

\section{Results}

In the 2 -year period under review, 82 children were treated for childhood malignancies, 44 males $(53.7 \%)$ and 38 females $(46.3 \%)$ giving a M:F ratio of 1.2:1. However, 60 cases with sufficient data, 35 males $(58.3 \%)$ and 25 females $(41.7 \%)$ were analysed. Their ages ranged from 3 months to 16 years. Under-fives constituted $55 \%$ of the study population (Table 1). 
Table 1. Age and gender distribution of the study population

\begin{tabular}{ccccccc}
\hline \multirow{2}{*}{$\begin{array}{c}\text { Age at } \\
\text { presentation }\end{array}$} & \multicolumn{2}{c}{ Sex } & \multicolumn{2}{c}{ Total } \\
\cline { 2 - 5 } & $\mathrm{N}$ & $\%$ & $\mathrm{~N}$ & $\%$ & $\mathrm{~N}$ & $\%$ \\
\hline 3 3 - 11 months & 2 & 3.3 & 1 & 1.7 & 3 & 5 \\
1 - 5 years & 18 & 30 & 12 & 20 & 30 & 50 \\
$6-10$ years & 8 & 13.3 & 10 & 16.7 & 18 & 30 \\
$11-16$ years & 7 & 11.7 & 2 & 3.3 & 9 & 15 \\
TOTAL & 35 & 58.3 & 25 & 41.7 & 60 & 100 \\
\hline
\end{tabular}

Figure 1 shows the socioeconomic status of the par- the patients were from middle and low income classes ents / care givers. Fifty-three and twenty-two percent of respectively.

Figure 1. Socioeconomic status of parents/ caregivers

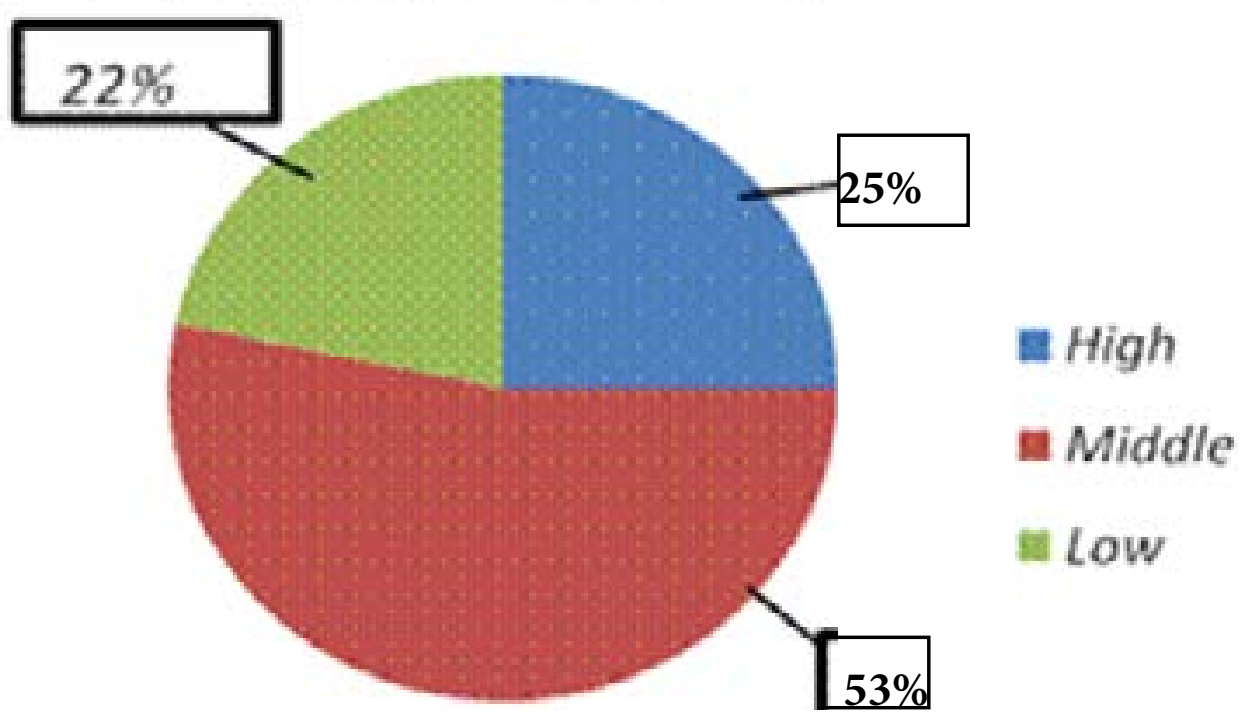

Table 2 shows that $27(45 \%)$ patients reported within 4 weeks of onset of symptoms while $16(26.7 \%)$ had been ill for more than 12 weeks before presentation.
The overall median duration of symptoms before presentation to our health facility was 8 weeks. More than half of the patients $(60 \%)$ presented with metastatic disease.

Table 2: Duration of illness before presentation and Presence of metastases at diagnosis

\begin{tabular}{lll}
\hline Duration of illness & Frequency & Percentage \\
\hline $0-4$ weeks & 27 & 45 \\
$5-8$ weeks & 11 & 18.3 \\
$9-12$ weeks & 6 & 10 \\
$=13$ weeks & 16 & 26.7 \\
Total & 60 & 100 \\
\hline Presence of metastasis & & \\
\hline Yes & 36 & 60 \\
No & 24 & 40 \\
Total & 60 & 100 \\
\hline
\end{tabular}


Figure 2 shows type of cancers and their frequency distribution. Commonest malignancies seen were Nephroblastoma: 20(33.3\%), Acute Leukaemias: 9(15\%), Lymphomas: 9(15\%), Rhabdomyosarcoma: 6(10\%) and
Neuroblastoma: 5(8.3\%). Others were Hepatoblastoma, Malignant fibrous histiocytosis, Malignant teratoma, Retinoblastoma, Hibernoma and Yolk sac tumour.

\section{Figure 2: Frequency distribution of cancers in children studied}

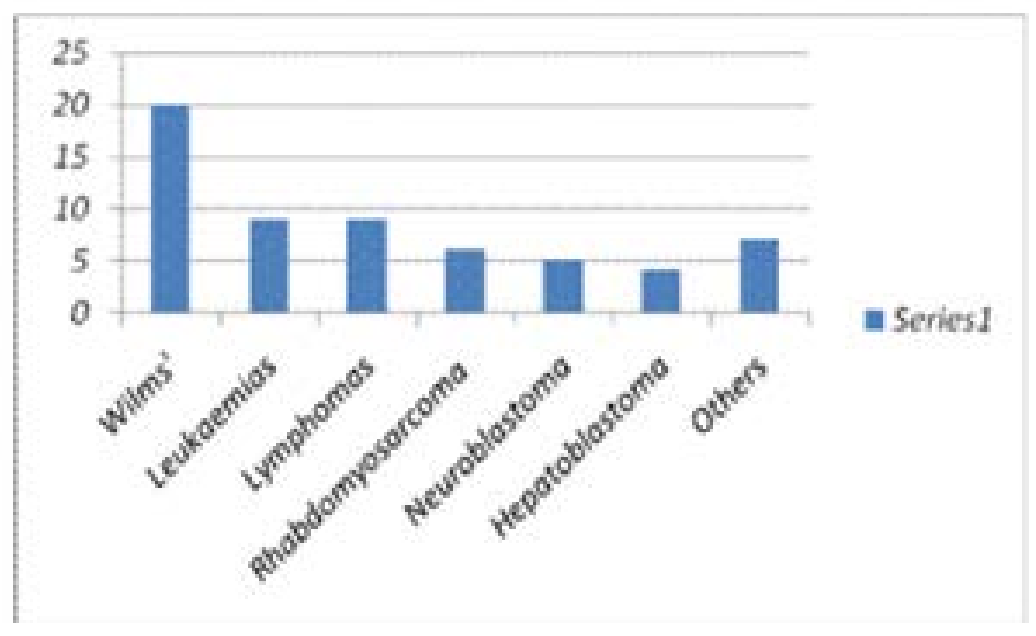

Table 3 summarises the treatment patients received. Fifty-two $(86 \%)$ patients had some forms of native treatment before presentation, which included massage, especially of abdomen, scarifications and/or herbal/alcohol-based concoctions. All patients benefited from supportive management during their hospital stay. Twenty-nine patients $(48.3 \%)$ received chemother- apy alone, $13(21.6 \%)$ had chemotherapy and surgery. Three patients $(5 \%)$ had surgery without chemotherapy of which 2 defaulted after surgery and 1 died before commencing chemotherapy. Only 1 child benefited at the end of life with aspects of palliative care including counselling of close family members who were all invited and were around the patient at the time of his demise.

Table 3: Treatment received

\begin{tabular}{lll}
\hline Treatment received & Frequency & Percentage \\
\hline $\begin{array}{l}\text { Native treatment } \\
\text { before presentation }\end{array}$ & 52 & 86 \\
Supportive treatment & 60 & 100 \\
Chemotherapy & 29 & 48.3 \\
Surgery & 16 & 26.6 \\
Chemotherapy \& & 13 & 21.6 \\
surgery & & \\
Palliative care & 1 & 1.6 \\
\hline
\end{tabular}

Table 4 shows the treatment outcome for various cancers. Twenty patients $(33.3 \%)$ defaulted with or without commencement of specific treatment, of which $5(8.3 \%)$ were lost to follow up and $15(25 \%)$ were discharged against medical advice (DAMA). Twenty-six (43.4\%) children died, the 3 commonest malignancies accounted for $60 \%$ (16) of them. Mortality rate was highest amongst children who had Leukaemias (55.5\%) and Lymphomas (55.5\%) compared to those who had Wilms' tumour (30\%). The difference was not statistically significant $(\mathrm{p}>0.05)$. 
Table 4: Frequency distribution of treatment outcome for commonest cancers

\begin{tabular}{llllrrr}
\hline Outcome & Wilms & Leukaemias & Lymphomas & Others & \multicolumn{2}{c}{ Total for all } \\
& & & & & $\mathrm{N}$ & $(\%)$ \\
\hline Completed treatment & 0 & 0 & 0 & 2 & 2 & 3.3 \\
Still on treatment & 5 & 1 & 2 & 2 & 10 & 16.7 \\
Lost to follow up & 1 & 0 & 0 & 4 & 5 & 8.3 \\
DAMA* & 6 & 3 & 2 & 4 & 15 & 25.0 \\
Died & 6 & 5 & 5 & 10 & 26 & 43.4 \\
Referred & 2 & 0 & 0 & 0 & 2 & 3.3 \\
\hline Total (\%) & $20(33.3)$ & $9(15)$ & $9(15)$ & $22(36.7)$ & 60 & $(100)$ \\
\hline
\end{tabular}

*DAMA $=$ Discharged against medical advice

\section{Discussion}

\section{Cancers and mortality}

Cancer remains an important cause of childhood morbidity and mortality in developing countries. ${ }^{4,5,6}$ The male preponderance observed in this study was comparable with previous reports in various parts of Nigeria, as well as in other resource-limited countries., ${ }^{4,6,13-16}$ Cultural and economic factors may account for the difference, as males usually benefit from more medical attention than females in these countries. ${ }^{15}$ While studies in India, ${ }^{4}$ Côte D'Ivoire ${ }^{13}$ and western parts of Nigeria ${ }^{16}$ found that children in the age bracket 5-9 years were most affected, under-fives children represented $55 \%$ of this study population. A similar finding was reported in an 11-year review of pattern of childhood malignant tumours in the South-West region of Nigeria where $54 \%$ of patients studied were under-fives. ${ }^{15}$ The series in Côte D'Ivoire ${ }^{13}$ studied 331 children with malignancies while that of Western parts of Nigeria ${ }^{16}$ had 978 children. These larger sample sizes may account for the variance observed in this study.

The socio-economic status of the affected families constitutes an important factor in determining the outcome of cancer treatment as revealed by the study of Byers et al in the United States of America, ${ }^{17}$ who found that cancer patients with low socioeconomic status have a higher risk of dying in the 5 years following cancer diagnosis. Moreover, cost is a recognised major obstacle to delivery of appropriate cancer management worldwide. $^{5}$

In this study, the majority of patients $(53 \%)$ were from the middle socio-economic class while $22 \%$ had low socio-economic background. This is at disparity with the studies of Shehu et $\mathrm{al}^{16}$ in Kano and Ile-Ife where $79.3 \%$ and $58.5 \%$ of the children studied were from the low socio-economic class respectively. This disparity may be attributed to the cosmopolitan nature of our environment with the oil industry as one of its major activities.

Notwithstanding, social supports are lacking in our setting and the financial burden of treatment of children with cancers is on the family as these patients do not benefit from either the free health care policy of the state where they reside and from where some of them are referred, or the National Health Insurance Scheme. Unfortunately, the latter does not consider care for terminal illnesses including all cancers as part of services it offers. ${ }^{18}$

It is therefore not surprising that many families of affected children have no access to or cannot afford to pay for the complete treatment of their children afflicted with cancers. This was also shown in Teheran, Iran where nearly all parents lacking health insurance coverage cited financial problems as a reason for discharging their children against medical advice, thereby interrupting their treatment and probably compromising treatment outcome. ${ }^{19}$ Furthermore, in Kenya where approximately $20-30 \%$ of the population is estimated to be covered with some forms of health insurance, ${ }^{20}$ Axt et al ${ }^{21}$ reported that patients with Wilms tumours enrolled in the National Health Insurance Fund showed better completion rate of therapy and better event-free survival than those not enrolled.

On the other hand, in El-Salvador, a lower middle-income country where the National Pediatric Cancer Program offered free treatment, a $22 \%$ rate of abandonment of treatment was still recorded.$^{22}$ Social conditions such as housing facilities in the city, economic support for transportation and basic family needs, and cultural factors were found to be implicated in the process of healing and thus associated with abandonment of treatment. These factors needed to be attended to for a favourable outcome. A similar approach is promoted 
in palliative care with one of its principles being a holistic approach of patients' care, addressing their physical, psychological, social and spiritual issues whatever the projected outcome $e^{7,8,9}$

\section{Late presentation}

Late presentation was observed in this study, with a median duration of symptoms of 8 weeks before presentation and majority of patients presenting with advanced diseases. This is a common finding in most parts of Africa and has been reported to have a negative impact on outcome of childhood cancers with an increased risk of mortality. ${ }^{5,14,16,23}$ Reasons for the late presentation were not ascertained in this study, although a high rate $(86 \%)$ of native treatment prior to presentation was found, which may be a reason amongst many others, and may reflect some of the socio-cultural practices in Nigeria. However, James et al in Ibadan ${ }^{14}$ who studied children with types of tumours comparable to those of this series identified delayed referrals, seeking health care from alternative sources and financial constraints as contributing factors to delayed diagnosis of childhood cancer.

Metastatic disease at diagnosis was found in $60 \%$ of cases in this series. This is lower than the $71.4 \%$ reported by Brown et $\mathrm{al}^{23}$ in an earlier study in Ibadan, but higher than $48.4 \%$ reported by James et $\mathrm{al}^{14}$ in the same hospital. Whereas Brown et $\mathrm{al}^{23}$ studied a larger number of children (88) with types of tumours also comparable to those of this study over a 7-year period, James et $\mathrm{al}^{14}$ had a smaller sample size over a shorter period and found no association between overall lag time- time between onset of symptoms and diagnosis, and presence of metastatic disease.

\section{Imperative for palliative care}

Late presentation with advanced disease stages place patients in difficult circumstances as many of them can only benefit from palliative care which is a new concept in our environment. Furthermore, the inadequate number of trained palliative care specialists, the lack of social supports and the inconsistent provision of opioids for effective pain control are amongst challenges still encountered in the effort to enhance the quality of life of these patients.

The commonest cancers in this study were nephroblastoma followed by acute leukaemias and lymphomas. All are childhood cancers known to have good prognosis in developed countries with cure rates above $85 \%{ }^{24}$ The rarity of brain tumours in this series has also been reported in a previous study in this same centre a decade ago $^{25}$ as well in several series in Nigeria. ${ }^{6,15,16}$ It is not clear whether this is due to biologic factors or it is possible that suspected cases are referred to centres with diagnostic and treatment facilities for central nervous system tumours.

A high mortality rate $(43.3 \%)$ was observed in this study. It is lower than the $59 \%$ reported by Brown et al ${ }^{23}$ in Ibadan. It is however higher than $21.7 \%$ obtained by Offiong in Abuja, ${ }^{6}$ who studied 46 cases of childhood malignancies over a 5 -year period. A greater number of referrals to the Ibadan centre may account for the larger sample size with higher mortality figure.

With a default rate of $33 \%$ in the current series, which would probably have adverse effects on treatment outcome, mortalities from childhood cancers in our environment may actually be higher than the rate observed in this study, as it is possible that when away from the hospital, defaulters would seek alternative care in churches, may end up with traditional healers or may even be abandoned to their fate. ${ }^{26}$ They may die at home in the midst of untold suffering. This is rather unfortunate as these children ought to benefit from palliative care services which holistically address all issues that cause distress to patients and their families, hence making dying less painful for both patient and family. ${ }^{7,8}$ Thus to relieve suffering within the context of a resource limited setting like ours, it is imperative to develop strategies for improvements in early diagnosis with reduction in morbidity and mortality, in tandem with the establishment and implementation of quality palliative care and palliative care policies.

\section{Conclusion}

There were more cases of cancer amongst under-fives with a male preponderance. Late presentation, poverty and high default rate were contributory factors to the poor outcome of most of the patients. Lack of palliative care left many families face their sufferings.

\section{Recommendations}

There is an urgent need for awareness campaign on childhood cancers targeted to parents and health workers to curtail late presentations. Implementation of 
palliative care and free treatment of childhood malignancies are advocated to improve outcome in our environment.

\section{Limitation}

Incomplete data was a major limitation in this study.

\section{Conflict of interest}

None

\section{Funding}

None

\section{Acknowledgement}

We acknowledge Dr J. Douglas and staff of the Health Records Department who assisted in retrieval of patients' case notes.

\section{References}

1. Ochicha O, Gwarzo AK, Gwarzo D. Pediatric malignancies in Kano, Northern Nigeria. World J Pediatr 2012; 8: 235- 239

2. Stones DK. Childhood cancer: Early warning signs. CME 2010; 28 (7): 314 - 316. PubMed

3. International Childhood Cancer Day - 15 February 2013 at educationscotland.gov.uk

4. Malik FR, Tahir A, Bashir H, Akhtar P. Spectrum of Paediatric Malignancies. Journal of Rawalpindi Medical College (JRMC); 2012;16:37-39

5. Kingham TP, Alatise OI, Vanderpuye V, et al. Treatment of cancers in sub-Saharan Africa. Lancet Oncol 2013; 14: e158-167

6. Offiong UM. Childhood malignancy in University of Abuja Teaching Hospital Gwagwalada, Abuja, Nigeria. Niger J Paed 2012; 39: 60-62

7. Merriman A, et al. Palliative Medicine: Pain and symptoms control in the cancer and/or HIV/AIDS patient in Uganda and other African countries. 4th edition, Kampala. Marianum Press Ltd 2006: 27- 42

8. Sepúlveda C, Marlin A, Yoshida T, Ullrich A. Palliative Care: The World Health Organization's Global Perspective. Journal of Pain and Symptom Management 2002; 24: 91-96

9. Mwangi-Powell F et al. Palliative Care in Africa. In: Ferrell B, Coyle N (Eds). Oxford Textbook of Palliative Nursing. 3rd edition, New York. Oxford University Press 2010: 1319-1330

10. Legal notice: Federal Republic of Nigeria Official Gazette No 2, Abuja 15th May 2009 Vol. 96. Page B 39-
40. Legal Notice on Publication of 2006 Census Final Results

11. Oyedeji GA. Socioeconomic and cultural background of hospitalized children in Ilesha. Nig J Paediatr 1985; 12: 111-117

12. Young JL Jr, Roffers SD, Ries LAG, Fritz AG, Hurlbut AA, (eds). SEER Summary Staging Manual-2000: Codes and Coding Instructions, National Cancer Institute, NIH Pub. No. 01-4969, Bethesda, MD, 2001: 11 13. Yao JJA et al. Childhood cancer in Côte d'Ivoire, 1995 - 2004 - PubMed challenges and hopes. S Afr Med J 2013;103:113-115

14. James BO, Ajayi SO, Ogun OA, Oladokun RE. Factors influencing time to diagnosis of childhood cancer in Ibadan, Nigeria. Afr Health Sci 2009; 9: 247-253

15. Agboola AOJ, Adekanmbi FA, Musa AA, et al. Pattern of childhood malignant tumours in a teaching hospital in south-western Nigeria. Med J Aust 2009; 190: 12-14

16. Shehu UA, Adegoke SA, Abdulsalam U, Ibrahim M, Oyelami OA, Adeodu OO. Pattern of childhood malignant, tumours in two tertiary teaching, hospitals in Nigeria: comparative study. Niger J Paed 2013; 40: 175 - 178 17. Byers T, Wolf HJ, Bauer KR, Bolick-Aldrich S, et al. The impact of socioeconomic status on survival after cancer in the United States: Findings from the National Program of Cancer Registries Patterns of Care Study. CANCER, Published Online: June 23, 2008 DOI: 10.002/cncr. 23567

18. National Health Insurance Scheme. Operational Guidelines 2005: 52-55

19. Roodpeyma S, Eshagh Hoseyni SA. Discharge of children from hospital against medical advice. World $J$ Pediatr 2010; 6: 355-356

20. Kumon K, Kaneko Y. Social and biological factors influencing the outcomes of children with Wilms tumors in Kenya and other Sub-Saharan countries. Transl Pediatr 2014; 3:42-46

21. Axt J, Abdallah F, Axt M, et al. Wilms tumor survival in Kenya. J Pediatr Surg 2013;48:1254-62.

22. Rossel N. "Don't you think it's better to trust God?" Perspective of parents abandoning therapy for their child with cancer. ttp://amma.socsi.uva.nl/theses/rossell\%20curco.pdf. Amsterdam Master's in Medical Anthropology (AMMA) 2010: University of Amsterdam 23. Brown BJ, Bamgboye EA, Sodeinde O. Causes of death in childhood cancer at the department of paediatrics, University College Hospital, Ibadan, Nigeria. Afr J Med Med Sci 2008; 37: 7-13 
24. Henze G, Weinberger H. Selected Schedules in the therapy of childhood cancers. 1st edition, Baxter Oncology Gmbh 2012. ISBN 978-927105-97-3

25. Seleye-Fubara D, Akani NA. Solid malignancies in children and adolescents: Experience at the University of Port Harcourt Teaching Hospital. Niger J Paed 2004; 31:43-47

26. Eke G, Opara P. Discharge against medical advice amongst patients admitted into the Paediatric wards of the University of Port Harcourt Teaching Hospital. Niger J Paed 2013; 40: 40-44 